\title{
Electronic Rapid Fitness Assessment: A Novel Tool for Preoperative Evaluation of the Geriatric Oncology Patient
}

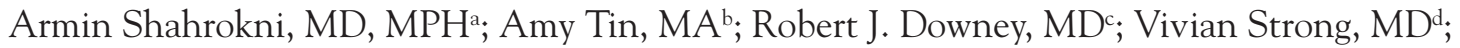 \\ Sanam Mahmoudzadeh, MDa; Manpreet K. Boparai, MS ${ }^{\mathrm{a}}$; Sincere McMillan, ANPa; Andrew Vickers, PhD; \\ and Beatriz Korc-Grodzicki, MD, PhD
}

\begin{abstract}
Background: The American College of Surgeons and American Geriatrics Society recommend performing a geriatric assessment (GA) in the preoperative evaluation of older patients. To address this, we developed an electronic GA, the Electronic Rapid Fitness Assessment (eRFA). We reviewed the feasibility and clinical utility of the eRFA in the preoperative evaluation of geriatric patients. Methods: We performed a retrospective review of our experience using the eRFA in the preoperative assessment of geriatric patients. The rate and time to completion of the eRFA were recorded. The first 50 patients who completed the assessment were asked additional questions to assess their satisfaction. Descriptive statistics of patient-reported geriatric-related data were used for analysis. Results: In 2015,636 older patients with cancer (median age, 80 years) completed the eRFA during preoperative evaluation. The median time to completion was 11 minutes (95\% $\mathrm{Cl}, 11-12$ minutes). Only $13 \%$ of patients needed someone else to complete the assessment for them. Of the first 50 patients, $88 \%$ (95\% $\mathrm{Cl}, 75 \%-95 \%)$ responded that answering questions using the eRFA was easy. Geriatric syndromes were commonly identified through the performance of the GA: $16 \%$ of patients had a positive screening for cognitive impairment, $22 \%(95 \% \mathrm{Cl}, 19 \%-26 \%)$ needed a cane to ambulate, and $26 \%(95 \% \mathrm{Cl}, 23 \%-30 \%)$ had fallen at least once during the previous year. Conclusions: Implementation of the eRFA was feasible. The eRFA identified relevant geriatric syndromes in the preoperative setting that, if addressed, could lead to improved outcomes.
\end{abstract}

J Natl Compr Canc Netw 2017;15(2):172-179

\section{Background}

Older patients (aged $>65$ years) with cancer have a higher risk of developing postoperative surgical complications, ${ }^{1}$ including delirium ${ }^{2}$ and prolonged hospital length of stay, ${ }^{3}$ and have poorer overall survival ${ }^{4}$ compared with younger patients. Although a significant number of studies have investigated the effects of age on surgical outcomes, others have argued that overall fitness, rather than age, should be the chief consideration in surgical decision-making. ${ }^{5}$ Frailty, as opposed to fitness, is a state of preexisting limited organ and functional reserve in response to stress (eg, surgery). ${ }^{6}$ Preoperative age-related deficits (or geriatric syndromes) have been shown to be associated with a higher risk of postoperative mortality, institutionalization, and delirium in

From ${ }^{a}$ Geriatric Service, Department of Medicine, ${ }^{b}$ Department of Biostatistics and Epidemiology, 'Thoracic Service, Department of Surgery, and ${ }^{\mathrm{d}}$ Gastric and Mixed Tumor Service, Department of Surgery, Memorial Sloan Kettering Cancer Center, New York, New York.

Submitted August 15, 2016; accepted for publication October 7, 2016.

The authors have disclosed that they have no financial interests,

arrangements, affiliations, or commercial interests with the manufacturers

of any products discussed in this article or their competitors. older patients undergoing cancer and noncancer-related surgery. ${ }^{7}$ Older patients with cancer with a slower walking pace, poorer nutritional status, higher number of medications taken, and more comorbid conditions have poorer surgical outcomes. ${ }^{8-10}$ A patient's level of frailty can be determined by geriatric assessment (GA), ${ }^{11}$ which is a multidimensional evaluation encompassing several functional and psychosocial domains. Various organizations have recommended incorporating GA into the assessment of older patients with cancer. ${ }^{12-14}$

Despite these recommendations, the inclusion of GA in the preoperative assessment of older patients with cancer has been poor. Recently, the Surgical Task Force at the International Society of Geriatric Oncology found that only $6 \%$ of clinicians used GA in daily prac-

This project was supported, in part, by the Beatriz and Samuel Seaver Foundation, the Memorial Sloan Kettering Cancer and Aging Program and $\mathrm{NIH} / \mathrm{NCl}$ Cancer Center Support Grant P30 CA008748.

This study was presented, in part, at the American Society of Clinical Oncology 2016 Annual Meeting.

Correspondence: Armin Shahrokni, MD, MPH, Geriatric Service,

Department of Medicine, Memorial Sloan Kettering Cancer Center, Box 205, 1275 York Avenue, New York, NY 10065. E-mail: shahroka@mskcc.org 
tice, and only $34 \%$ collaborated with geriatricians. ${ }^{15}$ These poor compliance rates likely stem from the practical difficulties of implementing GA in routine surgical practice.

To increase the rate of GA performance in the preoperative setting, we developed a patient-centered assessment that is feasible and effective, with no added burden for the provider. We have found that the key to successful implementation of this GA is to have patients complete it online, using an electronic tablet, with the results automatically collated and reported to the treating clinician. This article reviews our experience with the development and implementation of an electronic GA, the Electronic Rapid Fitness Assessment (eRFA).

\section{Materials and Methods}

\section{Data Collection and Analysis}

We performed a retrospective review of our institution's experience using the eRFA in the routine and elective preoperative evaluation of geriatric patients with cancer who presented to Memorial Sloan Kettering Cancer Center (MSKCC) geriatrics clinics in 2015. To assess and improve the quality of patient and/or caregiver interactions with the eRFA, data on time to complete the eRFA and the person who completed the eRFA were collected. The first 50 patients who completed the eRFA were asked additional questions to assess their satisfaction with the process. Descriptive statistics of patient-reported geriatric-related data were used for analysis. The Institutional Review Board at MSKCC approved this study.

\section{Referral to Geriatrics Service for Preoperative Assessment}

At MSKCC, patients aged $\geq 75$ years who are willing to be assessed by MSKCC Geriatrics Service, instead of their primary care provider, are referred to the Geriatrics Service. Surgeons may also refer younger patients who have geriatric syndromes (eg, cognitive deficits).

\section{Project Site}

The eRFA was developed at MSKCC through collaboration between the Geriatrics Service and the Web Survey Core Facility (Webcore). The Geriatrics Service performs preoperative assessments of approximately 900 older patients with cancer annually. The MSKCC Webcore is an NCI-funded core facil- ity that was created to develop and administer secure online questionnaires.

\section{Development of the eRFA}

During the eRFA development process, the Geriatrics Service held multiple discussions to determine which GA domains to assess and which validated assessment methods to use (Table 1). The name "Electronic Rapid Fitness Assessment" was selected to reflect the purpose of the GA, which is to distinguish patients who are fit from those who are frail.

\section{Administration and Reporting of the eRFA}

All patients who present to MSKCC geriatric clinics complete the eRFA while they are waiting to be seen by a geriatrician for their initial consultation. Patients may complete the eRFA on their own or with assistance from others (eg, a caregiver), or they may allow someone else (eg, a caregiver) to complete the assessment for them. Patients may also complete the eRFA at home, before their appointment, if they have Internet access and an e-mail account. After the assessment has been completed, a registered nurse (RN) performs a cognitive assessment using the Mini$\operatorname{Cog}^{16}$ and establishes the patient's mobility using the Timed Up and Go (TUG) ${ }^{17}$ test, the results of which are then entered into the eRFA by the RN.

The eRFA is accessible using computers, tablets, and smartphones. It is partially integrated with the electronic medical record (EMR), with patients' names and medical record numbers pulled from the EMR as patient-specific questionnaires are generated. After the patients complete the eRFA, clinicians can copy and paste the final report into their notes in the EMR under the GA subheading. For patients with significant GA deficits, geriatricians would include the eRFA report in the e-mail they send to the treating surgeons. Most of the time the impaired domains are highlighted and a postoperative action is emphasized. Moreover, the eRFA final report is included in the geriatrics preoperative clearance under the GA section for surgical teams to review in the postoperative period.

\section{Quality and Quantity Assurance}

The leader of the project (A.S.), with the help of the Webcore staff, has been responsible for monitoring the quality and quantity of the eRFAs. As a result of 
Shahrokni et al

Table 1. Electronic Rapid Fitness Assessment Domains and Instruments

\begin{tabular}{|c|c|c|}
\hline Domain & Assessment Tool & Description and Score Range (if Applicable) \\
\hline \multirow[t]{8}{*}{ Functional status } & $\begin{array}{l}\text { Karnofsky performance scale } \\
\text { (rated by the patient) })^{36}\end{array}$ & $\begin{array}{l}30-100, \text { in increments of } 10.30 \text { means severely disabled; } 100 \text { means normal without any } \\
\text { symptoms. }\end{array}$ \\
\hline & $A D L s^{37-39}$ & $\begin{array}{l}7 \text { activities: bathing, dressing, grooming, feeding, walking inside the home, walking outside } \\
\text { the home, and bladder and bowel control. Patients get } 2 \text { points for each activity that is not } \\
\text { limited at all, } 1 \text { point for limited a little, and } 0 \text { points for limited a lot. Total ADL score ranges } \\
\text { from } 0 \text { to } 14 \text {. }\end{array}$ \\
\hline & iADLs $s^{40,41}$ & $\begin{array}{l}8 \text { activities: telephone use, doing laundry, shopping, preparing meals, doing housework, } \\
\text { handling own medications, handling money and finances, and transportation to visit one's } \\
\text { doctor. Patients get } 2 \text { points for each activity that can be done without help, } 1 \text { point for } \\
\text { needing some help, and } 0 \text { point for being unable to do. Total iADL score ranges from } 0 \text { to } 16 \text {. }\end{array}$ \\
\hline & Timed Up and Go ${ }^{42-44}$ & $\begin{array}{l}\text { Patients are asked to get up from the chair, walk } 10 \text { feet, turn, and walk back to the chair } \\
(<10 \text { seconds, } 10-20 \text { seconds, }>20 \text { seconds). }\end{array}$ \\
\hline & \multirow{3}{*}{$\begin{array}{l}\text { History and number of falls } \\
\text { in the past year, context } \\
\text { of fall }\end{array}$} & - Falls in the past year (yes, no) \\
\hline & & - Number of falls in the past year $(1$ or $>1)$ \\
\hline & & - Context of last fall (inside or outside the home) \\
\hline & Use of assistive devices & Use of cane, walker, or wheelchair. \\
\hline Cognition & Mini-Cog test ${ }^{45}$ & $\begin{array}{l}\text { CDT and 3-word recall. Normal CDT gets } 2 \text { points, and each recalled word gets } 1 \text { point. Score } \\
\text { ranges from } 0 \text { to } 5 \text {. Score of } \leq 2 \text { is indicative of cognitive deficit. }\end{array}$ \\
\hline Social support & $\begin{array}{l}\text { Four-item Medical Outcomes } \\
\text { Study Social Support } \\
\text { Survey }\end{array}$ & $\begin{array}{l}\text { Four 5-point Likert scale questions addressing } 4 \text { domains of social support: emotional/ } \\
\text { informational, tangible, affectionate, and positive social interaction. Score for each item } \\
\text { ranges from } 1 \text { to } 5 \text {, and total score ranges from } 4 \text { to } 20 \text {. A higher score means better social } \\
\text { support. }\end{array}$ \\
\hline $\begin{array}{l}\text { Social activity } \\
\text { interference }\end{array}$ & $\begin{array}{l}\text { Medical Outcomes Study } \\
\text { Social Activity Survey }{ }^{47}\end{array}$ & $\begin{array}{l}\text { Three 5-point Likert scale questions addressing the interference of patient's health condition } \\
\text { with the social activity. Total score ranges from } 3 \text { to } 15 \text {. Higher score means more health- } \\
\text { related interference with social activities. }\end{array}$ \\
\hline \multirow[t]{2}{*}{ Emotional status } & Distress Thermometer ${ }^{48-52}$ & $\begin{array}{l}\text { Score ranges from } 0 \text { to } 10.0 \text { means no distress at all; } 10 \text { means extreme distress. Score of } \geq 4 \text { is } \\
\text { suggestive of high level of distress. }\end{array}$ \\
\hline & $\begin{array}{l}\text { Geriatrics Depression Scale } \\
\text { 4-item questionnaire }\end{array}$ & $\begin{array}{l}\text { Four yes/no questions regarding patient's psychological status. Score ranges from } 0 \text { to } 4 \text {, and } \\
\text { a score of } \geq 1 \text { is usually indicative of depression. }\end{array}$ \\
\hline Nutrition status & \multicolumn{2}{|c|}{$\begin{array}{l}\text { Single item on weight change during the past } 6 \text { months. Items range from "No weight change"/"Weight gain" to "Weight } \\
\text { loss of >20 lb." }\end{array}$} \\
\hline Vision & \multicolumn{2}{|c|}{$\begin{array}{l}\text { Questions about vision quality (excellent, good, fair, poor), wearing eyeglasses (yes, no), and effectiveness of eyeglasses in } \\
\text { improving vision (a great deal, somewhat, not at all). }\end{array}$} \\
\hline Hearing & \multicolumn{2}{|c|}{$\begin{array}{l}\text { Questions about hearing quality (excellent, good, fair, poor), wearing hearing aid (yes, no), and effectiveness of hearing aid in } \\
\text { improving hearing (a great deal, somewhat, not at all). }\end{array}$} \\
\hline \multirow[t]{2}{*}{ Polypharmacy ${ }^{30}$} & \multicolumn{2}{|c|}{ - Number of prescribed medications: $0,1-4,5-10,>10$} \\
\hline & \multicolumn{2}{|c|}{ - Number of herbals, supplements, and vitamins: $0,1-4,5-10,>10$. } \\
\hline
\end{tabular}

Abbreviations: ADLs, activities of daily living; $C D T$, clock-drawing test; iADLs, instrumental activities of daily living.

this process, the final report of the eRFA was revised to highlight missing data, and healthcare providers were asked to review the final report with the patients to make necessary corrections to ensure completion.

\section{Results}

\section{Pilot Phase}

Time to Complete the eRFA: The pilot phase of this project began in January 2015 and concluded in April 2015, with an average of 22 eRFA surveys completed each month for either preoperative assessment or other geriatric consultation. The median time to complete the eRFA was $15 \mathrm{~min}$ utes (95\% CI, 13-17 minutes), and $83 \%$ of patients (95\% CI, 73\%-90\%) were able to complete the eRFA in $\leq 25$ minutes.

Satisfaction Survey: To assess patient and caregiver satisfaction with the content and delivery of the eRFA, the first 50 patients who completed the eRFA were given a 16-item satisfaction questionnaire. The questionnaire included 3 sociodemographic questions (age, education, and sex); 3 technology questions (about the computer, the handheld device [eg, 
phones and tablets], and the availability of Internet access at home); and 10 questions regarding the patient's experience with the eRFA (Figure 1).

Of the 50 individuals who completed this questionnaire, $22 \%$ were aged $<75$ years, $30 \%$ were aged 75 to 79 years, $36 \%$ were aged 80 to 84 years, and $12 \%$ were aged $\geq 85$ years. A total of $64 \%$ were women, $38 \%$ had a high school diploma or less, $34 \%$ were college graduates or had some college education, and 28\% had an advanced degree. As shown in Figure 1, approximately $90 \%$ of patients (respective 95\% CI, 75\%-98\%) responded that answering questions, changing answers, and moving between questions were easy.

In response to the technology questions, 43 patients in the pilot study (86\%; 95\% CI, 73\%, 94\%) responded that they have a handheld device, computer at home, or Internet at home. Four patients reported that they disagreed with "not mind[ing] answering questions using the tablet," but only 2 of these 4 patients agreed that they would prefer to answer questions on paper over the tablet. Of the remaining 7 patients who did not report having any of the aforementioned technology, only 1 patient agreed that they would prefer answering questions on paper rather than on the tablet and none disagreed with "not mind[ing] answering questions using the tablet."

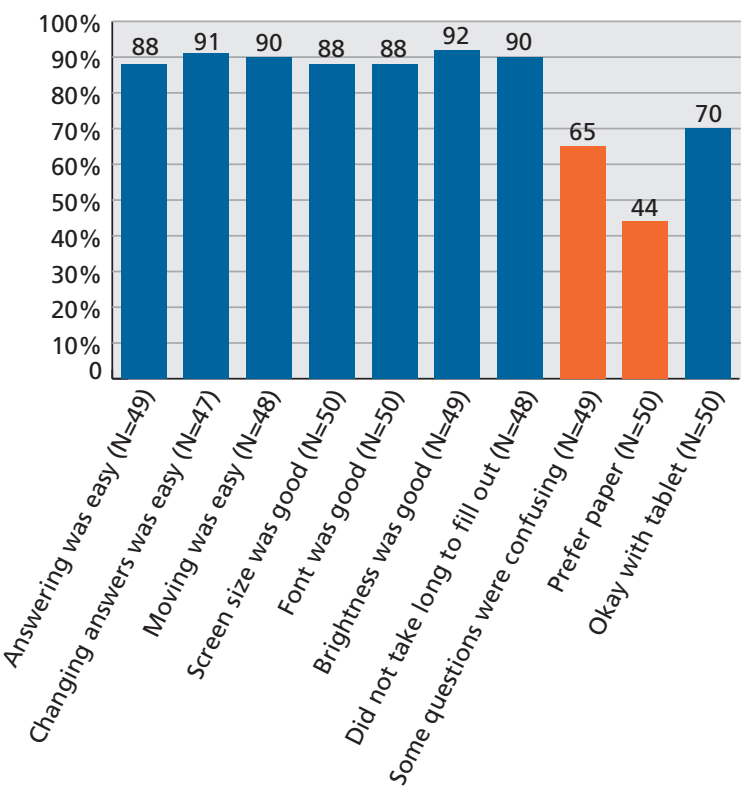

Figure 1. Patient satisfaction with the electronic rapid fitness assessment (blue bars represent strong and somewhat agreement; red bars represent strong and somewhat disagreement).

\section{Expansion Phase}

Use of the eRFA was expanded to all geriatric clinics in May 2015, leading to a significant increase in the number of monthly completions. In total, 1,024 older patients with cancer completed the eRFA, 636 of whom had presented to a geriatric clinic for preoperative assessment. Sociodemographic and clinical characteristics of the preoperative patient cohort are listed in Table 2.

The following sections summarize the additional data obtained by administration of the eRFA to these preoperative patients.

Completion of the eRFA: In this larger group, the median time to complete the eRFA was 11 minutes $(95 \%$ CI, 11-12 minutes), and 90\% (95\% CI, 88\%-93\%) of patients were able to complete the eRFA in $\leq 25$ minutes. Of the 636 preoperative eRFAs completed in $2015,50 \%$ were completed by the patients, $37 \%$ were completed with assistance, and $13 \%$ were completed by another person (likely a caregiver). Additionally, we were able to distinguish whether surveys were filled out in clinic or "home" (defined as anywhere outside of clinic) based on whether the user logged in with credentials, or if a member of the medical team (such as a research study assistant) signs in and hands off the device, thereby bypassing the patient's need to log in. Among this cohort, 59\% (95\% CI, 55\%, 63\%) of these surveys were accessed from home.

Comparison of Paper Format GA and eRFA: We compared the missing items in the paper-format GA that was completed by 283 patients in our institution in 2013 with the missing items in the eRFA. The missing rate for these 2 data collection methods was almost similar $(1.8 \%$ missing rate for activities of daily living [ADLs] in paper format vs $1.1 \%$ in the eRFA). On the other hand, cognitive assessment was missing for $3.5 \%$ of patients with paper-format GA compared with missing items for approximately $10 \%$ of patients completing the eRFA. This difference occurred as a result of change in the data entry process. For paper-format GA, clinicians were responsible for entering cognitive assessment data, whereas in the eRFA, nurses were responsible for data entry, which led to missing data, especially in the pilot and early expansion phase (see "Quality and Quantity Assurance," page 173).

eRFA Results Functional Domain: The median patient-rated Karnofsky performance scale score was 
Shahrokni et al

\begin{tabular}{|c|c|}
\hline Characteristic & N (\%) \\
\hline Age, median (interquartile range), y & $80(77-84)$ \\
\hline Female & $331(52)$ \\
\hline \multicolumn{2}{|l|}{ Marital status } \\
\hline Married & $338(53)$ \\
\hline Widowed & $180(28)$ \\
\hline Divorced & $50(8)$ \\
\hline Single & $44(7)$ \\
\hline Domestic partnership & $13(2)$ \\
\hline Separated & $9(1)$ \\
\hline Unknown & $2(<1)$ \\
\hline \multicolumn{2}{|l|}{ Education level } \\
\hline Advanced degree & $151(24)$ \\
\hline College graduate & $148(23)$ \\
\hline Some college & $108(17)$ \\
\hline High school diploma & $159(25)$ \\
\hline Less than high school diploma & $62(10)$ \\
\hline Unknown & $8(1)$ \\
\hline \multicolumn{2}{|l|}{ Living situation } \\
\hline Living with family or partner & $411(65)$ \\
\hline Living alone & $201(32)$ \\
\hline Living with someone who is not family/a partner & $7(1)$ \\
\hline Assisted living facility & $3(1)$ \\
\hline Nursing home & $1(<1)$ \\
\hline Other & $8(1)$ \\
\hline Unknown & $5(1)$ \\
\hline \multicolumn{2}{|l|}{ Race } \\
\hline White & $514(81)$ \\
\hline Black & $38(6)$ \\
\hline Asian & $25(4)$ \\
\hline Refused to answer & $44(7)$ \\
\hline Other & $4(1)$ \\
\hline Missing & $11(2)$ \\
\hline \multicolumn{2}{|l|}{ Surgery type } \\
\hline Ambulatory & $296(47)$ \\
\hline Surgery requiring hospitalization & $340(53)$ \\
\hline \multicolumn{2}{|l|}{ Surgical site } \\
\hline Genitourinary & $162(25)$ \\
\hline Head and neck & $85(13)$ \\
\hline Colorectal & $78(12)$ \\
\hline Gynecological & $60(9)$ \\
\hline Hepatopancreatic & $49(8)$ \\
\hline Breast & $36(6)$ \\
\hline Thoracic & $37(6)$ \\
\hline Gastric/mixed & $38(6)$ \\
\hline Ophthalmic & $33(5)$ \\
\hline Neurosurgery & $21(3)$ \\
\hline Orthopedic & $17(3)$ \\
\hline Other & $18(3)$ \\
\hline Unknown & $2(<1)$ \\
\hline
\end{tabular}

90 (range, 30-100). Overall, 26\% of patients (95\% CI, 23\%-30\%) experienced at least 1 fall during the previous year. Of these patients, 37\% (95\% CI, $30 \%-45 \%$ ) had more than one fall. Of the $161 \mathrm{pa}-$ tients who reported the location of the fall, a small majority experienced their last fall at home rather than outside the home ( $56 \%$ vs $44 \%$ ). In total, $22 \%$ (95\% CI, 19\%-26\%), 11\% (95\% CI, 9\%-14\%), and $4 \%(95 \% \mathrm{CI}, 3 \%-6 \%)$ of patients presented to the geriatric clinic using a cane, walker, or wheelchair, respectively. The time to complete the TUG test was $<10$ seconds in $56 \%$ of patients, 10 to 19 seconds in $23 \%$ of patients, and $>20$ seconds in $10 \%$ of patients. The remaining 74 patients had missing data (see "Quality and Quantity Assurance," page 173). Patients' levels of independence for ADLs and instrumental ADLs are shown in Figure 2.

Cognition: In total, $58 \%$ of patients were able to recall 3 words, $26 \%$ were able to recall 2 words, $12 \%$ were able to recall 1 word, and $4 \%$ could recall no words. Results of the clock-drawing test were abnormal for 146 (26\%). Overall, 16\% of patients had a positive screening for cognitive impairment (MiniCog score of $\leq 2$ ). It should be noted that 65 patients had missing data (see "Quality and Quantity Assurance," page 173).

Social Support and Social Activity Interference: Among our cohort, more patients expressed having adequate support (defined as all or most of the time) in the affectionate domain $(83 \%)$ than in positive social interaction $(75 \%)$, emotional/informational support $(71 \%)$, or tangible support (57\%). Responding to the impact of their health/emotional condition on their social activities, 39\% thought they were somewhat or much more limited than 6 months ago, and $24 \%$ thought they were somewhat or much more limited than their peers.

Emotional Status: The median distress score for this cohort was 4 , with $31 \%$ of patients ( $95 \%$ CI, $28 \%$ $35 \%$ ) experiencing a distress score of $\geq 6$. The median Geriatric Depression Scale 4-item score was 1.

Nutrition Status: In total, $44 \%$ reported no weight loss during the previous 6 months compared with $17 \%$ who lost $<5$ pounds, $17 \%$ who lost 5 to 10 pounds, $8 \%$ who lost 10 to 20 pounds, and $6 \%$ who lost $>20$ pounds; $7 \%$ did not know whether or by how much their weight changed during the previous 6 months. 
Geriatric Oncology Patients in Preoperative Period

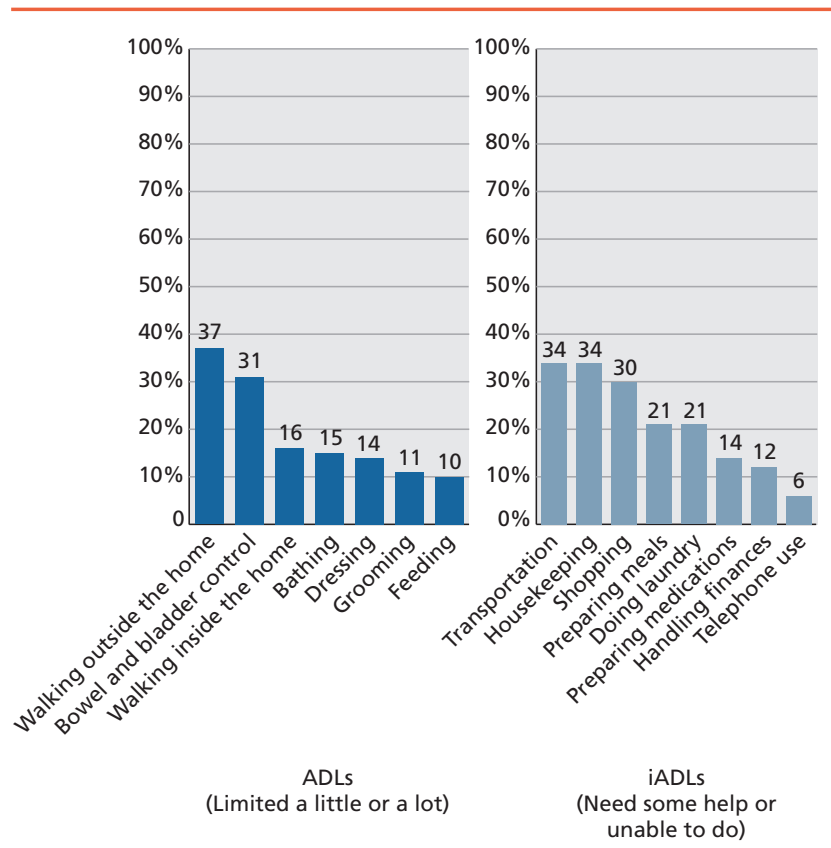

Figure 2. Patients' limitations in activities of daily living (ADLs) and instrumental activities of daily living (iADLs).

Sensory Deficit: Of the patients who presented for preoperative evaluation, $7 \%$ considered their vision quality to be poor, and 24\% considered their vision quality to be fair. Reported hearing quality was poor for $15 \%$ and fair for $27 \%$ of patients.

Polypharmacy: In total, $92 \%$ of patients took at least 1 medication. Among these patients, 50\% took 1 to 4 medications, $38 \%$ took 5 to 10 medications, and $5 \%$ took $>10$ medications; 40 patients did not provide details about the number of medications they took.

\section{Discussion}

To our knowledge, this is the first study to show the feasibility and utility of performing an electronic GA in the preoperative assessment of older patients with cancer. The median time to complete the eRFA for preoperative assessment was an acceptable $11 \mathrm{~min}$ utes, which is similar to the time it takes to complete a screening assessment (rather than a complete GA $)^{18}$ and is much shorter than the time reported to complete a paper-version GA (30 minutes). ${ }^{19}$ In addition, most patients were able to complete the eRFA on their own or with assistance from a caregiver. The number of missing items between the paper-format GA and eRFA were similar, which is consistent with what was reported in the prior literature. ${ }^{20}$ However, we showed the need for quality and quantity assurance in implementing electronic patient-reported outcomes. Simple interventions, such as reviewing missing items and educating staff about the importance of complete data entry, could be helpful in this setting. In order to develop the eRFA, we used the already available health information technology (HIT) infrastructure within our institution. We suggest that other investigators interested in implementing tools such as the eRFA assess the available HIT infrastructure within their institutions; use of those infrastructures may decrease the cost of developing such tools.

Through the use of the eRFA, aging-related deficits were discovered that otherwise might have gone unnoticed. Among our cohort, $16 \%$ had a positive screening for cognitive deficit. The incidence of cognitive deficit in our cohort is slightly higher than the incidence of cognitive deficit seen in the preoperative evaluation of 460 patients aged $\geq 70$ years reported previously (10.6\%). ${ }^{21}$ The difference could be reflective of age differences between the cohorts, because our cohort included patients aged $\geq 75$ years. Studies have shown that patients with cognitive deficits have a higher risk of postoperative delirium, ${ }^{22}$ which may lead to prolonged hospital stay and other complications. ${ }^{23} \mathrm{~A}$ substantial percentage of patients (37\%) had limitations walking outside the home, and expressed the need for assistance with transportation. These findings are important, because such limitations may jeopardize a patient's ability to adhere to postoperative follow-up recommendations by healthcare providers. Approximately $25 \%$ of our patients experienced at least 1 fall during the year before their surgical procedure. This is similar to the previously reported $21 \%$ incidence of falls in 111 patients (median age, 72 years) in the last 6 months before preoperative evaluation. ${ }^{10}$ This raises the need for postoperative physical therapy and home safety assessment for these patients. ${ }^{24}$

More than half of our patients expressed a high level of distress, indicating that interventions such as referral to a social worker should be considered. ${ }^{25}$ In total, $14 \%$ of patients experienced weight loss of $>10$ pounds during the previous 6 months, reflecting the need for nutritionist involvement. ${ }^{26}$ Poor or fair hearing quality, identified in $15 \%$ and $27 \%$ 
Shahrokni et al

of patients, respectively, may jeopardize patients' ability to understand care instructions, which may increase the likelihood of hospital readmission and functional decline. ${ }^{27,28}$ Polypharmacy was present in approximately $40 \%$ of patients; these patients are 2.4 times more likely to develop major postoperative morbidity. ${ }^{29}$ In a population of community-dwelling men aged $\geq 70$ years, polypharmacy was associated with an increased likelihood of frailty, disability, falls, and mortality. ${ }^{30}$ Therefore, conducting preoperative medication review to assess the appropriateness of the patient's medications is critical.

The correlation between frailty and surgical outcomes has been studied in older patients with cancer. In a study of 176 patients with colorectal cancer aged 70 to 94 years, postoperative complications and survival were strongly associated with frailty, which was defined as having one or more of the following conditions: ADLs dependency, severe comorbid conditions, cognitive deficit, depression, malnutrition, and taking $>7$ medications. ${ }^{31}$ Similarly, a study of 281 women with cancer aged $\geq 65$ years with an American Society of Anesthesiologists physical status classification system score of 1 or 2 found that multidimensional frailty score ${ }^{32}$ was associated with postoperative complications, increased likelihood of institutionalization, and prolonged hospital stay. ${ }^{33}$

Our study has several limitations. We tested the eRFA in a single institution with a patient population that may not be reflective of older communitydwelling patients elsewhere. Approximately 65\% of our cohort had at least some college education and were more likely to have Internet access. Studies have shown that, among older patients, higher education levels and more Internet access are associated with better acceptance of computers. ${ }^{34,35}$ The generalizability of our success needs to be tested in community clinics and among less-educated patients or those with less Internet access. Moreover, the
eRFA was included as part of a preoperative assessment within MSKCC's geriatric clinics. Additional challenges for implementing the eRFA in surgical oncology clinics need to be studied.

\section{Conclusions}

The highlight of our study is the development and successful implementation of the first patient-friendly electronic GA. Several future projects related to this work are planned. First, we will combine data obtained through the use of the eRFA with the MSKCC Surgical Outcomes Dataset to evaluate the correlation between aging-related deficits and surgical outcomes among older patients with cancer. Second, we will strive to implement the eRFA in all surgical oncology clinics at our institution so that older patients with cancer, regardless of whether they are referred to the Geriatrics Service, can be evaluated comprehensively. Finally, we will test the effectiveness of the eRFA in improving postoperative outcomes among older patients with cancer by conducting a prospective, randomized trial among this patient population.

\section{Acknowledgments}

The authors acknowledge the constant support of the Geriatrics Service registered nurses, nurse practitioners, physician office assistants, session assistants, and Webcore staff. They wholeheartedly appreciate the contributions of all of our older patients with cancer as well as their families and caregivers; without their collaboration, this project would not have been feasible. They appreciate the guidance from former Memorial Sloan Kettering Cancer Center Chair of the Department of Medicine, Dr. George Bosl.

\section{References}

1. Kaibori M, Ishizaki M, Matsui K, et al. Geriatric assessment as a predictor of postoperative complications in elderly patients with hepatocellular carcinoma. Langenbecks Arch Surg 2016;401:205-214

2. Hasegawa T, Saito I, Takeda D, et al. Risk factors associated with postoperative delirium after surgery for oral cancer. J Craniomaxillofac Surg 2015;43:1094-1098

3. Wright CD, Gaissert HA, Grab JD, et al. Predictors of prolonged length of stay after lobectomy for lung cancer: a Society of Thoracic Surgeons General Thoracic Surgery Database risk-adjustment model. Ann Thorac Surg 2008;85:1857-1865.

4. Finlayson E, Fan Z, Birkmeyer JD. Outcomes in octogenarians undergoing high-risk cancer operation: a national study. J Am Coll Surg 2007;205:729_ 734.

5. Manceau G, Karoui M, Werner A, et al. Comparative outcomes of rectal cancer surgery between elderly and non-elderly patients: a systematic review. Lancet Oncol 2012;13:e525-536.

6. Ferrucci L, Guralnik JM, Studenski S, et al. Designing randomized, controlled trials aimed at preventing or delaying functional decline and disability in frail, older persons: a consensus report. J Am Geriatr Soc 2004;52:625-634.

7. Oresanya LB, Lyons WL, Finlayson E. Preoperative assessment of the older patient: a narrative review. JAMA 2014;311:2110-2120. 
Geriatric Oncology Patients in Preoperative Period

8. Huisman MG, van Leeuwen BL, Ugolini G, et al. "Timed Up \& Go": a screening tool for predicting 30-day morbidity in onco-geriatric surgical patients? A multicenter cohort study. PLoS One 2014;9:e86863.

9. Cesari M, Cerullo F, Zamboni V, Di et al. Functional status and mortality in older women with gynecological cancer. J Gerontol A Biol Sci Med Sci 2013;68:1129-1133

10. Badgwell B, Stanley J, Chang GJ, et al. Comprehensive geriatric assessment of risk factors associated with adverse outcomes and resource utilization in cancer patients undergoing abdominal surgery. J Surg Oncol 2013;108:182-186.

11. Korc-Grodzicki B, Downey RJ, Shahrokni A, et al. Surgical considerations in older adults with cancer. J Clin Oncol 2014;32:2647-2653.

12. Hurria A, Wildes $T$, Blair SL, et al. Senior adult oncology, version 2.2014: clinical practice guidelines in oncology. J Natl Compr Canc Netw 2014;12:82-126.

13. Wildiers $H$, Heeren $P$, Puts $M$, et al. International Society of Geriatric Oncology consensus on geriatric assessment in older patients with cancer. J Clin Oncol 2014;32:2595-2603.

14. Chow WB, Rosenthal RA, Merkow RP, et al. Optimal preoperative assessment of the geriatric surgical patient: a best practices guideline from the American College of Surgeons National Surgical Quality Improvement Program and the American Geriatrics Society. J Am Coll Surg 2012;215:453-466.

15. Ghignone F, van Leeuwen BL, Montroni I, et al. The assessment and management of older cancer patients: a SIOG surgical task force survey on surgeons' attitudes. Eur J Surg Oncol 2016;42:297-302.

16. Borson S, Scanlan JM, Chen P, Ganguli M. The Mini-Cog as a screen for dementia: validation in a population-based sample. J Am Geriatr Soc 2003;51:1451-1454.

17. Podsiadlo D, Richardson $S$. The timed "Up \& Go": a test of basic functional mobility for frail elderly persons. J Am Geriatr Soc 1991;39:142-148.

18. Sattar S, Alibhai SM, Wildiers H, Puts MT. How to implement a geriatric assessment in your clinical practice. Oncologist 2014;19:1056-1068.

19. Williams GR, Deal AM, Jolly TA, et al. Feasibility of geriatric assessment in community oncology clinics. J Geriatr Oncol 2014;5:245-251.

20. Muehlhausen W, Doll H, Quadri N, et al. Equivalence of electronic and paper administration of patient-reported outcome measures: a systematic review and meta-analysis of studies conducted between 2007 and 2013 Health Qual Life Outcomes 2015;13:167.

21. PACE participants, Audisio RA, Pope D, et al. Shall we operate? Preoperative assessment in elderly cancer patients (PACE) can help. A SIOG surgical task force prospective study. Crit Rev Oncol Hematol 2008;65:156-163.

22. Deiner S, Silverstein J. Postoperative delirium and cognitive dysfunction Br J Anaesth 2009;103(Suppl 1):i41-46.

23. Korc-Grodzicki B, Sun SW, Zhou Q, et al. Geriatric assessment as a predictor of delirium and other outcomes in elderly patients with cancer Ann Surg 2015;261:1085-1090.

24. Pergolotti M, Williams GR, Campbell C, et al. Occupational therapy for adults with cancer: why it matters. Oncologist 2016;21:314-319.

25. Jacobsen PB, Ransom S. Implementation of NCCN distress management guidelines by member institutions. J Natl Compr Canc Netw 2007;5:99-103.

26. Rowan NR, Johnson JT, Fratangelo CE, et al. Utility of a perioperative nutritional intervention on postoperative outcomes in high-risk head \& neck cancer patients. Oral Oncol 2016;5442-5446.

27. Genther DJ, Betz J, Pratt $S$, et al. Association between hearing impairment and risk of hospitalization in older adults. J Am Geriatr Soc 2015;63:11461152 .

28. Chen DS, Betz J, Yaffe $K$, et al. Association of hearing impairment with declines in physical functioning and the risk of disability in older adults. J Gerontol A Biol Sci Med Sci 2015;70:654-661.

29. Pujara D, Mansfield P, Ajani J, et al. Comprehensive geriatric assessment in patients with gastric and gastroesophageal adenocarcinoma undergoing gastrectomy. J Surg Oncol 2015;112:883-887.

30. Gnjidic D, Hilmer SN, Blyth FM, et al. Polypharmacy cutoff and outcomes: five or more medicines were used to identify community-dwelling older men at risk of different adverse outcomes. J Clin Epidemiol 2012;65:989_ 995.
31. Kristjansson SR, Rønning B, Hurria A, et al. A comparison of two preoperative frailty measures in older surgical cancer patients. J Geriatr Oncol 2012;3:1-7.

32. Kim S, Han H, Jung $H$, et al. Multidimensional frailty score for the prediction of postoperative mortality risk. JAMA Surg 2014;149:633-640.

33. Choi JY, Yoon SJ, Kim SW, et al. Prediction of postoperative complications using multidimensional frailty score in older female cancer patients with American Society of Anesthesiologists physical status class 1 or 2. J Am Coll Surg 2015;221:652-660.e2.

34. Vroman KG, Arthanat S, Lysack C. "Who over 65 is online?" Older adults' dispositions toward information communication technology. Comput Human Behav 2015;43:156-166.

35. Shahrokni A, Mahmoudzadeh S, Saeedi R, Ghasemzadeh H. Older people with access to hand-held devices: who are they? Telemed J E Health 2015;21:550-556.

36. Mor V, Labiberte L, Morris JN, Wiemann M. The Karnofsky performance status scale. An examination of its reliability and validity in a research setting. Cancer 1984;53:2002-2007.

37. Katz S, Downs TD, Cash HR, Grotz RC. Progress in development of the index of ADL. Gerontologist 1970;10:20-30.

38. Hartigan I. A comparative review of the Katz ADL and the Barthel Index in assessing the activities of daily living of older people. Int J Older People Nurs 2007;2:204-212.

39. Katz S, Ford AB, Moskowitz RW, et al. Studies of illness in the aged. The index of ADL: a standardized measure of biological and psychosocial function. JAMA 1963;185:914-919.

40. Lawton MP, Brody EM. Assessment of older people: self-maintaining and instrumental activities of daily living. Gerontologist 1969;9:179-186.

41. Hoppe S, Rainfray M, Fonck M, et al. Functional decline in older patients with cancer receiving first-line chemotherapy. J Clin Oncol 2013;31:38773882 .

42. Bohannon RW. Reference values for the timed up and go test: a descriptive meta-analysis. J Geriatr Phys Ther 2006;29:64-68.

43. Guideline for the prevention of falls in older persons. American Geriatrics Society, British Geriatrics Society, and American Academy of Orthopaedic Surgeons Panel on Falls Prevention. J Am Geriatr Soc 2001;49:664-672.

44. Yeung TS, Wessel J, Stratford PW, MacDermid JC. The timed up and go test for use on an inpatient orthopaedic rehabilitation ward. J Orthop Sports Phys Ther 2008;38:410-417.

45. Borson S, Scanlan J, Brush M, et al. The mini-cog: a cognitive 'vital signs' measure for dementia screening in multi-lingual elderly. Int J Geriatr Psychiatry 2000;15:1021-1027.

46. Gjesfjeld CD, Greeno CG, Kim KH. A confirmatory factor analysis of an abbreviated social support instrument: the MOS-SSS. Res Social Work Prac 2008;18:231-237

47. Stewart AL. Measuring Functioning and Well-Being: The Medical Outcomes Study Approach. Durham, NC: Duke University Press; 1992.

48. Hegel MT, Collins ED, Kearing S, et al. Sensitivity and specificity of the Distress Thermometer for depression in newly diagnosed breast cancer patients. Psychooncology 2008;17:556-560.

49. Roth AJ, Kornblith AB, Batel-Copel L, et al. Rapid screening for psychologic distress in men with prostate carcinoma. Cancer 1998;82:1904-1908.

50. Mitchell AJ. Pooled results from 38 analyses of the accuracy of distress thermometer and other ultra-short methods of detecting cancer-related mood disorders. J Clin Oncol 2007;25:4670-4681.

51. Ransom S, Jacobsen PB, Booth-Jones M. Validation of the Distress Thermometer with bone marrow transplant patients. Psychooncology 2006;15:604-612.

52. Holland JC, Bultz BD. The NCCN Guideline for Distress Management: a case for making distress the sixth vital sign. J Natl Compr Canc Netw 2007;5:3-7.

53. Pomeroy IM, Clark CR, Philp I. The effectiveness of very short scales for depression screening in elderly medical patients. Int J Geriatr Psychiatry 2001;16:321-326. 